Date of Issue: December 31, 1986

$Y--2358$

Distribution Category: UC-25

DE87 004775

\title{
ASSESSMENT OF ELECTROCHEMICAL POTENTIOKINETIC REACTIVATION TESTS TO QUALIFY STAINLESS STEEL FOR NITRIC ACID SERVICE
}

\author{
A. R. Olsen \\ J. J. Dillon \\ A. H. Peters \\ T. L. Clift \\ Metals and Ceramics Department \\ Y-12 Development Division
}

\section{DISCLAIMER}

This report was prepared as an account of work sponsored by an agency of the United States Government. Neither the United States Government nor any agency thereof, nor any of their employees, makes any warranty, express or implied, or assumes any legal liability or responsibility for the accuracy, completeness, or usefulness of any information, apparatus, product, or process disclosed, or represents that its use would not infringe privately owned rights. Reference herein to any specific commercial product, process, or service by trade name, trademark, manufacturer, or otherwise does not necessarily constitute or imply its endorsement, recommendation, or favoring by the United States Government or any agency thereof. The views and opinions of authors expressed herein do not necessarily state or reflect those of the United States Government or any agency thereof.

Prepared by the

Oak Ridge $Y-12$ Plant

P.O. Box Y, Oak Ridge, Tennessee 37831

operated by

MARTIN MARIETTA ENERGY SYSTEMS, INC. for the

U.S. DEPARTMENT OF ENERGY

under contract DE-AC05-84OR21400
This document is

PLiBLICLY RELEASABLE Bang Stuel.

Authorizing Official

Date: $\quad 2-23 \cdot 07$ 


\section{DISCLAIMER}

This report was prepared as an account of work sponsored by an agency of the United States Government. Neither the United States Government nor any agency Thereof, nor any of their employees, makes any warranty, express or implied, or assumes any legal liability or responsibility for the accuracy, completeness, or usefulness of any information, apparatus, product, or process disclosed, or represents that its use would not infringe privately owned rights. Reference herein to any specific commercial product, process, or service by trade name, trademark, manufacturer, or otherwise does not necessarily constitute or imply its endorsement, recommendation, or favoring by the United States Government or any agency thereof. The views and opinions of authors expressed herein do not necessarily state or reflect those of the United States Government or any agency thereof. 


\section{DISCLAIMER}

Portions of this document may be illegible in electronic image products. Images are produced from the best available original document. 


\section{CONTENTS}

ABSTRACT ........................ 1

SUMMARY........................ 1

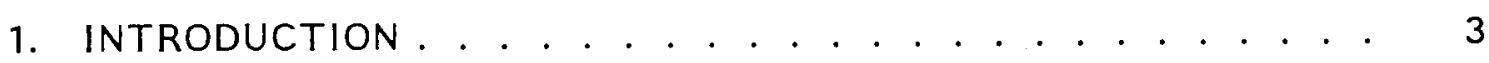

2. ASSESSMENT FINDINGS . . . . . . . . . . . . . . 5

2.1 Literature Search . . . . . . . . . . . . . . . . . 5

2.2 Experimental Study. . . . . . . . . . . . . . . . . . 8

2.3 Screening Test Procedures . . . . . . . . . . . . . . . . 8

2.4 Screening Test Results . . . . . . . . . . . . . . . . 11

3. DISCUSSION OF FINDINGS. . . . . . . . . . . . . . 18

4. CONCLUSIONS. . . . . . . . . . . . . . . 25

REFERENCES .................... . . . 26 


\begin{abstract}
To minimize the costs and delivery time delays associated with purchasing type $304 \mathrm{~L}$ stainless steel materials for service in nitricacid-containing media, an alternative to the current Oak Ridge Y-12 Plant requirement of testing in accordance with American Society for Testing and Materials (ASTM) A 262, Practice $C$ (the boiling nitric acid test), is being sought. A possible candidate is the electrochemical potentiokinetic reactivation (EPR) test being developed for the nuclear industry and under consideration for acceptance as an ASTM standard. Based on a review of the literature and some limited screening tests, this test, as currently proposed, is not a suitable substitute for the nitric acid test. However, with additional development the EPR test is a likely candidate for providing a quantitative substitute for the current qualitative oxalic acid etching (ASTM A 282, Practice A) often used to accept, but not reject, materials for use in a nitric acid medium.
\end{abstract}

\title{
SUMMARY
}

A number of processes at the Oak Ridge Y-12 Plant involve nitricacid-containing media. In general, good performance has been obtained by using austenitic stainless steels as the materials of construction, provided they have passed the established nitric acid test, American Society for Testing and Materials (ASTM) A-262, Practice C. Unfortunately, this test requires specimens of each lot to be subjected to fresh, boiling, concentrated nitric acid through five separate 48-h periods, a process that increases costs and can result in delivery delays. ASTM A-262 includes other standard practices developed in part to speed the testing of the stainless steels' susceptibility to intergranular attack, but none of these is as reliable as Practice $C$, where the intended use involves a nitric acid medium. Because of the significant amount of stainless steel components purchased by the Y-12 Plant, one task in general corrosion evaluation is the identification and evaluation of an alternative test procedure that would require less time and be less expensive than Practice $C$. This need has been emphasized by the increased rate of purchases associated with current process upgrading and improvement programs, such as the Enriched Uranium Recovery Improvement (EURI).

One potential test procedure being considered for inclusion in the ASTM standards is the electrochemical potentiokinetic reactivation (EPR) test. The EPR test evolved from concentrated efforts to devise a method for nondestructive quantitative measurements of intergranular sensiti-zation of stainless steels because of the occurrences of stresscorrosion cracking in nuclear power plants. This report addresses our assessment of the current EPR procedures as candidates for replacing the nitric acid test. This assessment is based on a thorough literature search and a series of screening experiments conducted sporadically between January 1984 and July 1985. 
The EPR test being considered by the ASTM involves two variant procedures involving a common electrolyte and current measurements derived from controlled potential sweeps of a polarized sample. The sample may be a separate specimen or an isolated polished section of a component. The single-loop practice developed by $W$. L. Clarke and coworkers* measures the charge integral obtained in sweeping the potential from the passive to the active region. After normalization to the grain boundary area of the specimen, the resulting coulombs per square centimeter, identified as the $P_{a}$ value, is used as a measure of sensitization. Some experimenters have used the peak current achieved during this potential sweep as the measure of sensitization. The double-loop practice suggested by Akashi et al. $t$ involves a double potential sweep. Starting at the rest (corrosion) potential, the applied voltage is raised to a fixed passive potential and then back from the passive to the active region. The ratio of the peak current on the return sweep $I_{R}$ to the peak current on the forward sweep $I_{A}$ is used to define the degree of grain boundary sensitization. Published comparisons indicate the two practices provide comparable results with some specimen preparation and reproducibility advantages indicated for the double-loop practice.

The literature search revealed numerous cases of the experimental usage of the EPR test on standard grades of austenitic steel in comparisons with various ASTM A-262 practices, welding research, alloycasting studies, and even material production process adjustments. However, there were no direct comparisons with the nitric acid test. This lack of direct comparison, together with the paucity of data on the low-carbon grades of austenitic stainless steel that are usually used in the Y-12 Plant, led to the limited screening tests performed as part of this assessment.

The objective of the screening tests was to provide, if possible, a comparison of EPR data with the standard nitric acid test data for various degrees of sensitization of the low-carbon steels, particularly the type $304 \mathrm{~L}$ stainless steel. To provide a range of degrees of sensitization, available plate material was sensitized for various times at temperatures between 650 and $675^{\circ} \mathrm{C}$. The results of these comparability tests and a variety of attempted correlations are reported. In our limited testing program, we were unable to establish a useful correlation, partly because with our low-carbon materials we were unable to establish intermediate levels of sensitization. Our heat treatments produced either no significant change in the nitric acid corrosion rates or very severe sensitization.

Based on the findings of our literature search and the limited screening tests, the currently proposed EPR procedures should not be used at this time as a substitute for the established nitric acid corrosion test. However, if a standardized practice is established for industry, the EPR test might very well provide a quantitative means of accepting, but not rejecting, material lots without requiring the nitric acid test.

*Reference 5 .

†Reference 6. 


\section{INTRODUCTION}

One of the subtasks of general corrosion evaluation is the identification and evaluation of alternative procedures for the acceptance of stainless steel components to be used in systems involving a nitric acid medium. Justification for this investigation derives from the significant amount of materials and components purchased for the Y-12 Plant. This need has been emphasized by the increased rate of purchases associated with the Enriched Uranium Recovery Improvement Program (EURI).

Although austenitic stainless steels are generally quite corrosion resistant in most aqueous environments, they are susceptible to intergranular attack when sensitized and to both intergranular and transgranular stress-corrosion cracking. In addition, certain components may be subject to end-grain attack. Though the causes of end-grain attack are not well defined, there is evidence that it derives in part from the segregation of intermetallic and nonmetallic compounds, such as slag or sulfides, in the ingot. During subsequent forming, these compounds are elongated to form stringers or inclusions. When a surface perpendicular to the axis of the stringers is exposed to certain corrodents, significant attack will occur along the stringers. Exposure of the surface perpendicular to the stringers may occur (1) in the ends of piping assembled with socket welds, (2) on the faces of flanges machined from bar stock, or (3) on portions of the surfaces of valve stems, plugs, or balls machined from rounds or bars.

Nitric-acid-containing media can and do lead to the above localized forms of attack. Therefore, Practice $C$ of the American Society for Testing and Materials (ASTM) A-262 standard recommended practices for detecting susceptibility to intergranular attack in stainless steels is usually specified when the material is to be exposed to such media. Although the results of this test cannot be used to predict the corrosion rates in the various media, they do provide assurance that there is no significant sensitivity to localized forms of attack. When combined with purchaser-specified upper limits of attack, usually $0.94 \mathrm{~mm} /$ year (0.024 in./year), they also indicate the product will provide the needed degree of corrosion resistance. The other standard practices in ASTM A-262 are either qualitative or do not reveal certain forms of localized attack. M. A. Streicher published (1978) an excellent review of the existing evaluation tests for intergranular corrosion of stainless steels. ${ }^{1}$

The established nitric acid test, ASTM A-262, Practice C, is the oldest of the standardized procedures for detecting the susceptibility of a given lot of stainless steel to intergranular attack. Although the ASTM A-262 standard includes other tests, none has proven as reliable where the intended service involves exposure to nitric acid media. The Y-12 Plant's experience has been good for materials that have been purchased with the nitric acid test required as part of the acceptance criteria. The difficulty with this requirement is the reluctance of 
material suppliers to provide this test because of the costs and delivery time delays. These effects are the results of the requirements of the Practice $C$ procedures that define five separate 48-h tests in fresh solutions of boiling $65 \%$ nitric acid with intermediate weighings of carefully prepared coupons. For the low-carbon grades, commonly specified where welding is required, the coupon preparation includes a sensitization heat treatment of $1 \mathrm{~h}$ at $675^{\circ} \mathrm{C}\left(1250^{\circ} \mathrm{F}\right)$ prior to surface preparation and area determination.

Because of the time and costs associated with this procedure and the severity of this test, alternative practices have been defined by ASTM and are included in ASTM A-262. Of these, the only one commonly used for material intended for nitric acid service is Practice $A$, the oxalic acid etch test for the classification of etch structures of stainless steels. Practice $A$ is a qualitative screening test that can be used to accept but not to reject a given lot. The qualitative nature of this test makes it highly questionable for approving materials for use in critical applications. A further limitation is its inability to identify the susceptibility to intergranular attack in nitric acid solutions caused by sigma formation in molybdenum containing grades of stainless steel such as types $316,316 \mathrm{~L}, 317$, or $317 \mathrm{~L}$.

The objectives of this subtask were to identify and evaluate alternative test procedures that would require less calendar time and be less expensive than the current ASTM Practice C. Of particular interest was an electrochemical test known as the electrochemical potentiokinetic reactivation (EPR) test, which is being considered for inclusion in the ASTM standards.

Based on an early EPR-proposed standard and a limited search of the literature, a series of screening experiments was initiated in January 1984. This procedure was considered necessary because the reported data were based on the standard grades of stainless steel, and Y-12's interest was in the low-carbon grades. Because the initial literature search showed no comparisons of the EPR test with the Practice $C$ nitric acid test, the literature search was expanded, and other researchers were contacted for any useful unpublished data. 


\section{ASSESSMENT FINDINGS}

\subsection{LITERATURE SEARCH}

Stress-corrosion cracking occurrences in nuclear power plant components $^{2}$ led to an increased effort on the nondestructive quantitative measurements of sensitization of stainless steels. As part of this activity, W. L. Clarke and coworkers ${ }^{3}$ compared two existing ASTM standard practices with an EPR method. They concluded that the oxalic acid etch (Practice $A$ ) and the EPR methods saturated at high degrees of sensitization; however, Practice $E$ (the copper-copper sulfate, sulfuric acid test) retained its discriminating capabilities at high degrees of sensitization, but was not suitable for detecting lower degrees of sensitization.

Because the EPR approach offers a nondestructive quantitative testing method, there has been a significant amount of continuing investigation in the United States and abroad. An apparatus was developed for field use to test welds," and a standard practice procedure was proposed for acceptance by ASTM. ${ }^{5}$ This procedure, the single-loop practice, involves measuring the charge integral obtained from a polarized sample subjected to a controlled potential sweep from the passive to the active region in a specific electrolyte. After normalization to the grain boundary area (GBA) of the specimen, the resulting coulombs per square centimeter, identified as the $P_{a}$ value, is used as a measure of sensitization. A variant of this technique, used by some experimenters, uses the peak current achieved during the potential sweep as the measure of sensitization. A modified version of the single-loop practice was suggested by Akashi et al. ${ }^{6}$ This double-loop practice is initiated at the rest (corrosion) potential, and the controlled potential sweep is raised to a fixed passive potential and then back from the passive to the active region. The ratio of the peak currents achieved during the two sweeps is used to define the degree of grain boundary sensitization.

A recent comparison by Majidi and Streicher ${ }^{7}$ of the single- and double-loop practices clearly indicates that the two provide comparable results. This same report indicates two clear advantages for the double-loop practice: the results are more reproducible and are less sensitive to certain test procedures, such as scan rates and, particularly, specimen surface finish. Although the test conditions should be constantly maintained for comparable results, the reduced requirements for sample surface-finish preparation and the elimination of the need for posttest microscopic examination to identify any pitting, (required by the single-loop test) are significant practical advantages. Majidi and Streicher ${ }^{7}$ have also compared both EPR practices with existing ASTM standard test practices $A$ and $B$ (the ferric sulfate-sulfuric acid test). Although their results show that the EPR tests, particularly the doubleloop test, can clearly distinguish between the three Practice A step, duplex, and ditch structures, they do not measure the relative extent of sensitization once the higher levels associated with the ditched structure are formed. Conversely, the Practice $B$ test can distinguish between higher degrees of sensitization but is insensitive in the lower 
degrees. Because the lower degrees of sensitization are the important areas for stress-corrosion cracking in the oxygenated water media of the nuclear power plants, some modification of the EPR test is likely to become an ASTM standard, at least for this application. Unfortunately, none of the experimental data reported in these programs provided a comparison with the nitric acid test.

In addition to the efforts on developing the EPR test for the nuclear industry, other groups have published significant data on its application in other areas. Lorias-10 has addressed its utility in the fabrication industry, and The University of Tennessee experimenters are employing it in studies supported by the Steel Founders Society of America (SFSA) and the Welding Research Council (WRC). Although these studies have not been aimed at improving the methodology, they have provided significant comparative data.

In these 1979 papers ${ }^{*} 9$ Loria addressed the use of Jominy bars to evaluate the heat-to-heat variations in the susceptibility of type 304 stainless steel to sensitization. He then showed the relation of these tests to production for 1- to 5-in.-diam bar stock. Although only limited EPR testing was done, the results seem to be more definitive than the oxalic acid etch tests used to measure sensitization as a function of cooling rate. Here are two of his primary findings relevant to our evaluation.

1. Continuous-cooling sensitization (CCS) measurements from a Jominy quench bar test can be correlated with time-temperature sensitization (TTS).

2. Sensitization is easier to produce by cooling from the 800 to $950^{\circ} \mathrm{C}$ range than from the 1000 to $1100^{\circ} \mathrm{C}$ range (confirming some data of Solomons ${ }^{11}$ ). A third finding-that argon-oxygen decarburization (AOD) heats of type 304 stainless steel with their higher nitrogen contents $(0.06$ to $0.10 \mathrm{wt} \%)$ than electric furnace heats $(0.03$ to 0.045 wt $\frac{\circ}{0}$ of $\mathrm{N}_{2}$ ) are less susceptible to sensitization-has been noted by a number of investigators. ${ }^{11}$

The data presented in Loria's technical note 10 of August 1981 furnish the most encouragement for developing an EPR method to provide a quantitative substitute for the existing qualitative oxalic acid etch screening test and, possibly, for the nitric acid test itself. He describes tests with type 304 stainless steel that utilize the Jominy bar method to provide CCS data and compares the results of oxalic acid etching with single-loop EPR tests. Although the number of data points is limited, a pattern of correlation is evident. The pattern is more distinct for the heat that showed significant end-grain attack, which indicates that the single-loop EPR test may be sensitive to features such as the concentration of nonmetallic inclusions that are normally only of concern for nitric acid applications. This result was also evident in some indirect comparisons of single-loop EPR results with nitric acid tests given in this same publication. The trend lines as a function of carbide precipitation rating ${ }^{11}$ were shown to be quite similar. The EPR data for this comparison were obtained by varying 
the sensitization time at $650^{\circ} \mathrm{C}$ from 2 to $30 \mathrm{~min}$. These specimens also showed deep end-grain pitting but little grain-boundary attack in the oxalic acid etch test. The data from the bar stock made from an AOD production heat did not show significant end-grain pitting, and the comparison between the oxalic acid etch and the EPR data was less clear. Although the $\mathrm{P}_{a}$ values for the EPR tests rose steadily with reduced cooling rates, the percent of ditched grain boundaries in the oxalic acid tests appeared to remain essentially constant over a range of cooling rates before abruptly increasing. Because this bar not only had fewer nonmetallic inclusions but also a higher nitrogen content, ${ }^{12}$ the cause of this behavior is difficult to define. The data do suggest that the lower carbon, cleaner, type $304 \mathrm{~L}$ stainless steels may also go through an abrupt change in the degree of sensitization. Because the single-loop EPR $P_{a}$ values rose above the current $P_{a}$ limit established for nuclear reactor stress-corrosion cracking (SCC) concerns before ditching occurred, a higher $P_{a}$ limit might be acceptable for nitric acid applications. Such a $P_{a}$ value would have to be established experimentally.

In October 1982, Loria published a perspective paper ${ }^{13}$ in which he described a modification of the Jominy test adapted by Giacobbe and associates at Superior Tube Company to screen materials and to eliminate from production fast carbide precipitation lots or to modify the processing procedures to quench fast enough to prevent sensitization. The adaptation involves packing $3 / 8$-in.-wide $(9.5 \mathrm{~mm})$ by $3 / 8$-in. maximum thickness $(9.5 \mathrm{~mm})$ by 6 -in.-long $(24.2-\mathrm{cm})$ strips into a center cavity of a type 304 stainless steel holder with external dimensions that match the Jominy bar design. The assembly is held together with screws, and it uses shims to ensure tight packing; it uses asbestos cement to seal the unit. Thermocouple monitoring indicated no change in the standard distribution of Jominy bar cooling rates.

The SFSA has funded work at The University of Tennessee on the sensitization of cast stainless steels. The initial abjective of Project A-82/85 was to investigate the need for postweld repair solution heat treatment. The research, under the direction of $E$. E. Stansbury and C. D. Lundin, has been summarized in a masters thesis by S. J. Pawel. " The research concentrated on the CF (304) and CFM (316) duplex alloys. The compositions included a range of carbon content from 0.015 to $0.8 \%$ with three generic ferrite levels of $\sim 5,12$, and $18 \%$. Specimens were tested in the as-cast, solution heat-treated, and weldsimulation heat-treated conditions. Both single- and double-loop EPR tests were compared with the oxalic acid etch test (A-262 A) and the ferric sulfate-sulfuric acid test (A-262 B). In general, the EPR test results compared well with the A-262 B tests results on a pass-or-fail basis. Of particular significance, however, are the exceptions.

The single-loop EPR results for CF 3 alloys in the as-cast and weld-simulated conditions all failed because of significant pitting while passing the A-262 B test. The low and intermediate ferrite number as-cast CF3M alloys also failed the single-loop EPR while passing the A-262 B test, but severe pitting was not noted. Only two of these tests (low-ferrite CF 3 alloy), failed the double-loop EPR test, and 
these failures were marginal. The results suggest that the specificity of the double-loop test to carbide precipitation at the grain boundaries is better. The results also suggest that the appropriate calibration of the single-loop test may be better for comparison with the nitric acid test (A-262 C), where corrosion associated with end grains, inclusions, and sigma is important.

A limited amount of testing with the A-262 C nitric acid test was reported as part of this program. The comparative EPR data, based on single-loop, peak-current values was not reported, but the general statement was that the EPR results indicated "a very low degree of chromium depletion."15 These results were only screening experiments, and additional experimentation that will provide more comparative data for EPR vs nitric acid tests with these duplex alloys is currently under way. Limited screening tests were also conducted with two CF3, one CF8, and one CF8M alloy, using the Jominy bar CCS technique. The reported findings indicate a good comparison between the EPR and oxalic acid etch tests, but only the CF8 alloy showed any significant degree of sensitization. Because the bars were quenched from the very high temperature of $1120^{\circ} \mathrm{C}$, this result may explain the unexpected lack of any sensitization of the CF8M alloy. Sensitization had been noted in weld thermal-cycle testing.

The single-loop EPR test is also being compared with ASTM A-262, Practice $A$, as a means of detecting weld sensitization in a program supported by the WRC at The University of Tennessee. Under the direction of C. D. Lundin and E. E. Stansbury, this program has the objective of determining the range of welding variables for which corrosion resistance will not be reduced to an unacceptable level in type 304 stainless steel and proposing alternative materials for use in the nuclear industry. ${ }^{16,17}$ Although no comparisons with other quantitative measurements of sensitization have been reported, the EPR method is apparently providing significant heat-affected zone sensitization profiles.

\subsection{EXPERIMENTAL STUDY}

Concurrent with the literature search, a screening experimental program was conducted to provide a comparison of EPR data with nitric acid corrosion test data for type $304 \mathrm{~L}$ stainless steel. As indicated in the Introduction, the bulk of the data on EPR testing has been with the standard higher carbon grades of stainless steel, and direct comparisons with the nitric acid test have not been reported. The objective of the screening experiments was to provide, if possible, a comparison of EPR data with the standard nitric acid test (ASTM A-262 C) data for various degrees of sensitization of the low-carbon steels. With such a comparison, an EPR test value might possibly be defined for the acceptance of a given lot of material.

\subsection{SCREENING TEST PROCEDURES}

To provide a range of degrees of sensitization, the screening tests were conducted using available type $304 \mathrm{~L}$ and 316 stainless steel plate materials that were sensitized for various times at temperatures in the 
650 to $675^{\circ} \mathrm{C}$ range, where maximum chromium carbide precipitation occurs. A 1 -h sensitization at this temperature is commonly required for specimens of extra low carbon or for stabilized grades of austenitic steels before they are subjected to the nitric acid corrosion test.

After heat treatment, the plate sections were machined to provide rectangular coupons for corrosion testing and small circular specimens for the EPR tests. Corrosion coupons were typically $2.54 \times 5.1 \times 0.3 \mathrm{~cm}$ $(1 \times 2 \times 1 / 8 \mathrm{in.})$ specimens with a hole near one end for suspending them in a flask. In a limited number of cases, EPR-size disks were corrosion tested to confirm earlier results. The nitric acid corrosion tests were conducted in accordance with ASTM A-262, Practice C.

The EPR disks were circular specimens $1.6 \mathrm{~cm}(0.625$ in.) in diameter and $3.2 \mathrm{~mm}$ ( $0.125 \mathrm{in.})$ thick. This size was dictated by the available sample holder used for these tests. Both single- and double-loop EPR procedures were employed in making the EPR tests, and the same solution and apparatus were used for both procedures. The test solution was $0.05 \mathrm{M}$ of sulphuric acid $\left(\mathrm{H}_{2} \mathrm{SO}_{4}\right)$ and $0.01 \mathrm{M}$ of potassium theo-cyanide $\mathrm{KSCN}$ at $30 \pm 1^{\circ} \mathrm{C}$. The solution was deaerated with nitrogen gas by purging at a rate of $150 \mathrm{~cm}^{3} / \mathrm{min}$ before and during the test. A scan rate of $1.66 \mathrm{mV} / \mathrm{s}(6 \mathrm{~V} / \mathrm{h})$ was used. The corrosion cell, as specified in ASTM-G 5, was a 1-L, five-neck flask with two high-density graphite counter electrodes and a saturated calomel reference electrode positioned by a salt bridge with a glass tip near the specimen surface. A Princeton Applied Research Corporation (PARC) Model 350 corrosionmeasurement console with a built-in integrator and an IR compensation unit was used to conduct the EPR tests. The specimen holder, as supplied by PARC, is constructed of a fluorocarbon and uses a Kalrez sealing washer to limit the exposed surface area of the disk to $1 \mathrm{~cm}^{2}$. With this arrangement only one test was lost because of holder leakage, and there was no indication of crevice corrosion at the sealing surface.

Some of the early single-loop tests were conducted with specimen surfaces polished on 600-grit silicon carbide ( $\mathrm{SiC}$ ) paper. Subsequent single-loop tests and all all double-loop tests used surfaces with a final $0.05 \mu \mathrm{m}$ aluminum oxide $\left(\mathrm{Al}_{2} \mathrm{O}_{3}\right)$ polish.

The procedure for conducting the single-loop test followed those proposed by Clarke. ${ }^{5}$ The specimen was held in the solution until the open-circuit (rest) potential was established. This condition usually occurred in $\sim 2 \mathrm{~min}$ and provided a potential of $-400 \mathrm{mV} \pm 100 \mathrm{mV}$. For the $304 \mathrm{~L}$ materials the range was from -420 to $-480 \mathrm{mV}$; the one sensitization series run on type 316 stainless steel ranged from -320 to $-400 \mathrm{mV}$. This value of E-corrosion (zero external current flow) is recorded, and the specimen potential is rapidly raised to $+200 \mathrm{mV}$ and held there for 2 min to passivate the surface. The reactivation scan is then initiated, and the current is recorded continuously with the changing voltage dropping back to the rest potential. A single-loop scan from our test series is shown in Fig. 1. Figure 2 is a schematic curve of the reactivation polarization curve, showing the parameters of interest in the singleloop EPR test. ${ }^{5}$ The integrated current (coulombs) from the Flade potential to the rest potential $\left(E_{\text {corr }}\right.$ ) is then used as a measure of the 


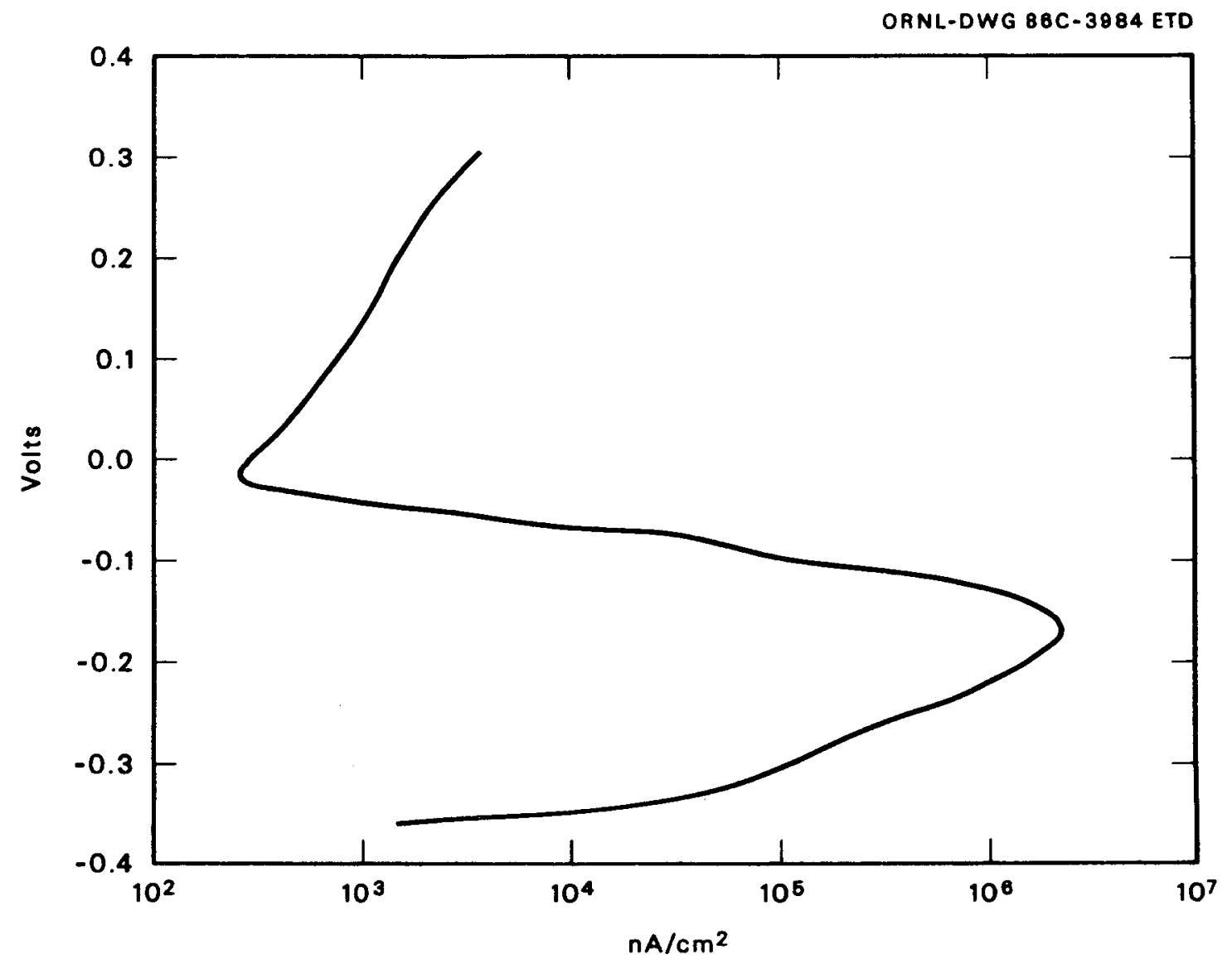

Fig. 1. Typical single-loop EPR test curve (type 304L stainless steel sensitized at $650^{\circ} \mathrm{C}$ for $3.5 \mathrm{~h}$ ).

susceptibility of material to intergranular corrosion. Because the regions normally corroded during this scan are the grain boundaries sensitized by chromium depletion resulting from chromium carbide precipitation, the measured integrated current $(Q)$ is usually normalized to the area of these grain boundaries. The GBA is estimated by utilizing the ASTM grain size $(X)$ to define the length of exposed grain boundaries per unit area, and there is an assumed average grain boundary width of $5 \times 10^{5} \mathrm{~cm}$. Thus, given the specimen area (As), the GBA can be calculated from the following formula:

$$
\operatorname{GBA}\left(\mathrm{cm}_{2}\right)=\text { As }\left[5.09544 \times 10^{-3} \exp (0.34696 X)\right] \text {. }
$$

Dividing $Q$ by the GBA then provides a measure of merit in terms of coulombs per square centimeter, usually designated as $\mathrm{P}_{\mathrm{a}}$. The lower this value, the lower the amount of reactivated grain boundary corrosion attack.

The double-loop test procedure (as proposed by Akashi et al. ${ }^{6}$ ) is initiated in the same manner as the single-loop test with the establish. ment of the open circuit (rest) potential. However, at this point the 


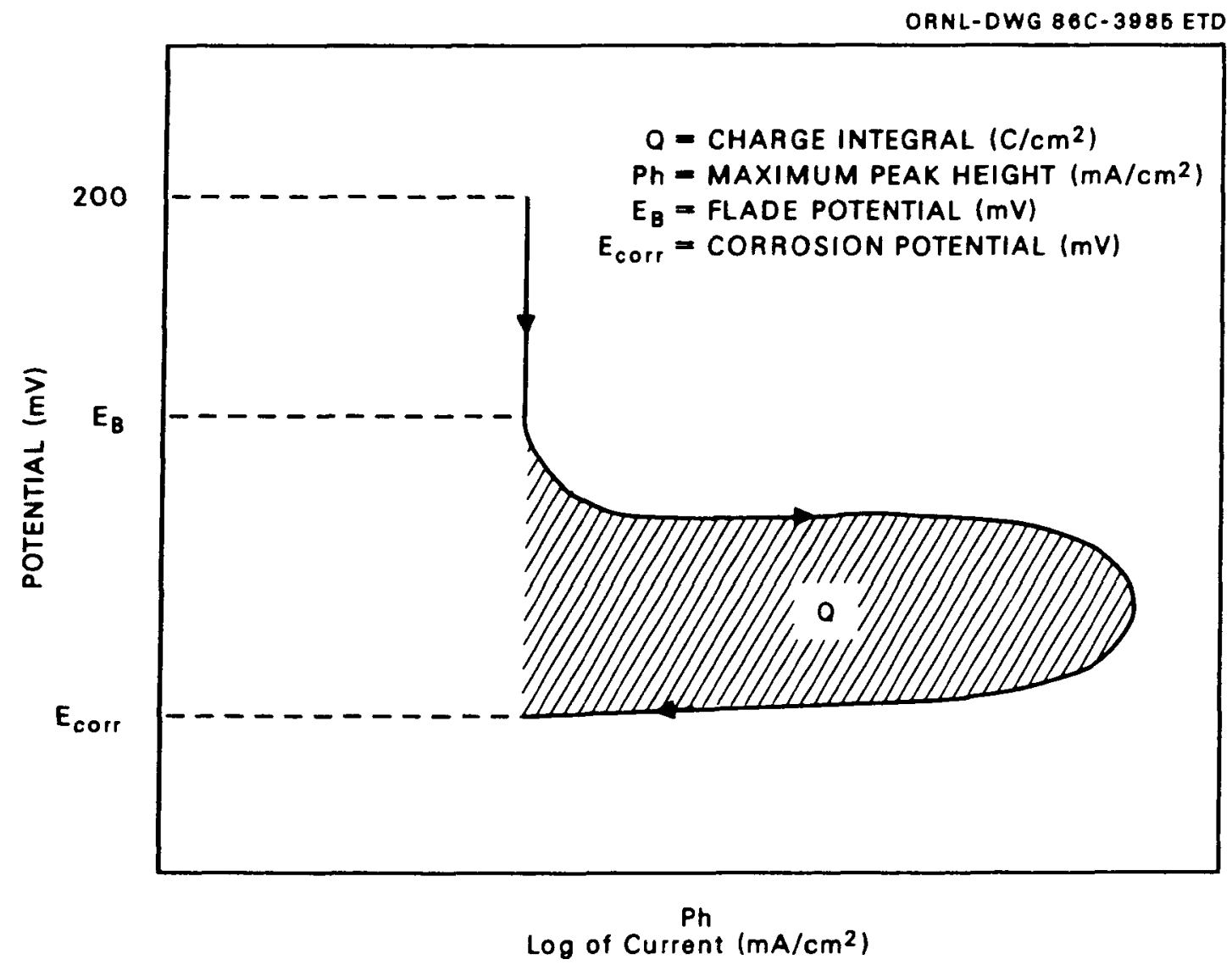

Fig. 2. Schematic of reactivation polarization curve showing parameters of interest for single-loop EPR testing.

specimen potential is then scanned at the rate of $1.66 \mathrm{mV} / \mathrm{s}$ up to a potential of $300 \mathrm{mV}$ and then immediately back at the same rate to the rest potential. The current as a function of voltage during the entire scan period is recorded. A double-loop scan from our test series is given in Fig. 3. The peak currents achieved during the initial forward anodic scan $\left(I_{A}\right)$ and the reverse reactivation scan $\left(I_{R}\right)$ are then ratioed to provide a figure of merit. The lower the $I_{R} / I_{A}$ ratio, the lower the intergranular attack. This ratio may also be normalized using the estimated GBA (determined by the same formula discussed in the previous paragraph) by normalizing the $I_{R}$ values to the GBA and by dividing the $I_{A}$ values by the specimen area. The primary advantage of the doubleloop procedure is the reduced sensitivity to variations in surface preparation. ${ }^{7}$

\subsection{SCREENING TEST RESULTS}

Chemical analyses for the plate materials used in the screening tests are given in Table 1. The ASTM grain sizes determined for these materials are also included in Table 1 . There was no evidence of grainsize changes during the various sensitization heat treatments. The nearly identical chemical analyses of the plates (WR 7763 and WR 7698) suggest they came from the same heat with the WR 7698 material having been solution heat-treated at a high temperature to provide the large grain size. Unfortunately, we have been unable to document this. 


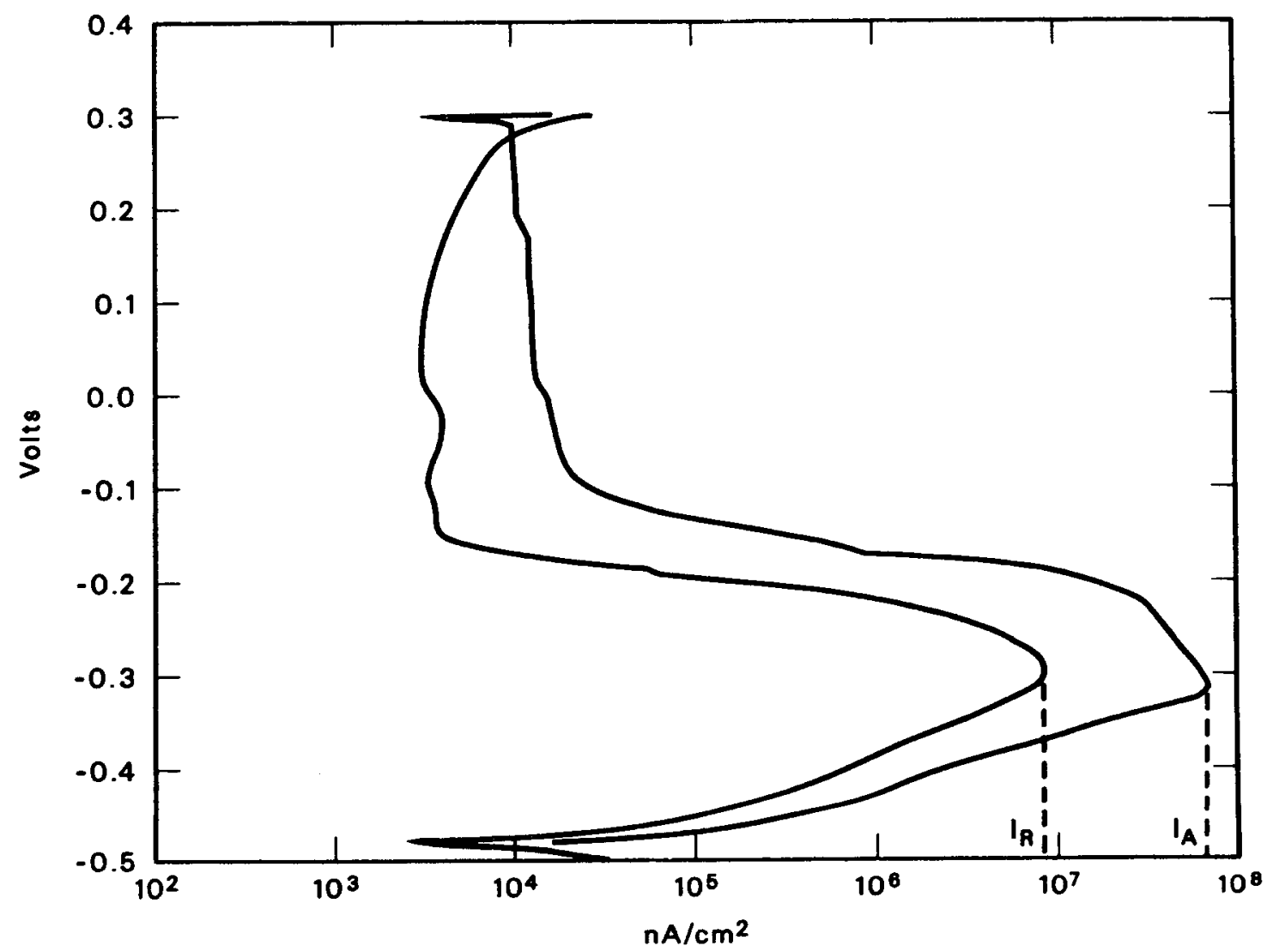

Fig. 3. Typical double-loop EPR test curve (type 304L stainless steel sensitized at $650^{\circ} \mathrm{C}$ for $4.0 \mathrm{~h}$ ).

Table 1. Chemical composition and grain size of plate stock used in EPR screening tests

\begin{tabular}{|c|c|c|c|c|}
\hline \multirow[b]{2}{*}{ Element } & \multicolumn{4}{|c|}{$\begin{array}{c}\text { Compositions of different plate types } \\
\left(\text { wt o } \frac{0}{0}\right)\end{array}$} \\
\hline & $\begin{array}{l}304 \mathrm{~L} \\
\text { WR } 7763 \\
(7.5)^{a}\end{array}$ & $\begin{array}{c}304 \mathrm{~L} \\
\text { WR } 7796 \\
(6)\end{array}$ & $\begin{array}{c}304 \mathrm{~L} \\
\text { WR } 7698 \\
(3)\end{array}$ & $\begin{array}{c}316 \\
\text { WR } 7884 \\
(3.5)\end{array}$ \\
\hline Chromium & 18.15 & 18.22 & 18.22 & 17.24 \\
\hline Nickel & 8.66 & 8.77 & 8.72 & 13.05 \\
\hline Carbon & 0.0269 & 0.0100 & 0.0277 & 0.0435 \\
\hline Manganese & 1.85 & 1.66 & 1.85 & $<0.01$ \\
\hline Silicon & 0.41 & 0.56 & 0.41 & 0.06 \\
\hline Phosphorus & 0.241 & 0.0390 & 0.0220 & 0.0083 \\
\hline Sulfur & $\mathrm{NA}^{b}$ & NA & NA & NA \\
\hline Molybdenum & 0.20 & 0.26 & 0.20 & 2.19 \\
\hline Nitrogen & 0.0710 & 0.0946 & 0.0716 & 0.0595 \\
\hline Copper & 0.30 & 0.21 & 0.30 & 0.01 \\
\hline
\end{tabular}

$a_{\text {Numbers }}$ in parentheses are ASTM grain sizes.

bNA: not available. 
The screening experiments were done on the basis of the time available-therefore, intermittently-over a period of 18 months. Consequently, the data are grouped in four segments with, varying thermal sensitization heat treatments. The signficant data for each group are represented in Tables 2 through 5 . The heat-treatment variations in these tables represent our chronological search for the appropriate time in the sensitization temperature range necessary to provide intermediate degrees of sensitivity. Only the single-loop EPR tests were run initially. The double-loop tests were run at the end of the experimental program.

The surface preparation of the EPR specimens was initially restricted to 600-grit paper $(\sim 17 \mu \mathrm{m})$ because this is the minimum degree of polishing defined by Clarke, ${ }^{5}$ and specimen preparation was to be minimized. The tests reported by Majidi and Streicher ${ }^{18}$ showed that the degree of polishing could have an effect on distinguishing between degrees of sensitization. Their single-loop EPR data did show increasing $\mathrm{P}_{\mathrm{a}}$ values with decreasing surface roughness for highly sensitized specimens and an inverse relationship for solution-annealed material. Because of this information and the erratic $P_{a}$ values obtained from the 600-grit polished specimens (Tables 2 and 3 ), coupled with the desire to separate various degrees of sensitization, the degree of surface finishing was improved. A change to polishing with $6 \mu \mathrm{m}$ alumina was made, followed by $0.5 \mu \mathrm{m}$ alumina. This metallographic sample type of finish was subsequently used on all EPR specimens. Reported data indicate a 600-grit polish is adequate for the double-loop EPR procedure. All EPR samples were polished after the heat treatment. 
Table 2. Comparative EPR test data for type 304L stainless steel plate; Work Request 7763 (grain size 7.5)

\begin{tabular}{|c|c|c|c|c|c|c|c|c|c|c|c|}
\hline \multirow{2}{*}{$\begin{array}{l}\text { Test } \\
\text { type } \\
a\end{array}$} & \multicolumn{2}{|c|}{ Sensitization } & \multirow{2}{*}{$\begin{array}{c}\text { Specimen } \\
\text { surface } \\
\text { finish }\end{array}$} & \multicolumn{2}{|c|}{ Peak currents } & \multicolumn{2}{|c|}{$\begin{array}{c}\text { Reactivation } \\
\text { integrated current }\end{array}$} & \multicolumn{2}{|c|}{ Current ratios } & \multicolumn{2}{|c|}{ Corrosion test data } \\
\hline & $\begin{array}{c}\text { Temperature } \\
\left({ }^{\circ} \mathrm{C}\right)\end{array}$ & $\begin{array}{l}\text { Time } \\
(h / \mathrm{min})\end{array}$ & & $\underset{(\mu A)}{I_{R}}$ & $\begin{array}{c}I_{A} \\
(\mu A)\end{array}$ & $\begin{array}{c}Q \\
\text { (C) }\end{array}$ & $\underset{\left(\mathrm{C} / \mathrm{cm}^{2}\right)}{P_{A}}$ & $\begin{array}{c}\text { As read } \\
I_{R} / I_{A}\end{array}$ & $\begin{array}{c}\text { Normalized } \\
I_{R} / I_{A}\end{array}$ & $\begin{array}{l}\text { avera } \\
\text { [mm/year }\end{array}$ & $\begin{array}{l}\text { ge rate } \\
\text { (mils/year)] }\end{array}$ \\
\hline SL & 649 & $8 / 0$ & 600 -grit SiC & $1.72 \times 10^{4}$ & $N M^{b}$ & 1.267 & 18.4 & & & 3.45 & (136) \\
\hline SL & 649 & $8 / 0$ & 600 -grit $\mathrm{SiC}$ & $1.1 \times 10^{4}$ & NM & 1.114 & 16.2 & & & 3.45 & (136) \\
\hline SL & 649 & $8 / 0$ & $0.05 \mu \mathrm{m} \mathrm{A1},{ }_{3}$ & $3.98 \times 10^{4}$ & NM & 2.769 & 40.2 & & & 3.45 & (136) \\
\hline SL & 649 & $8 / 0$ & $0.05 \mu \mathrm{m} \mathrm{A1}{ }_{2}{ }^{3}$ & $4.25 \times 10^{4}$ & NM & 2.939 & 42.7 & & & 3.45 & (136) \\
\hline SL & 649 & $4 / 0$ & 600 -grit SiC & $9.54 \times 10^{3}$ & NM & 0.647 & 9.4 & & & 2.84 & (112) \\
\hline SL & 649 & $4 / 0$ & 600 -grit SiC & $1.1 \times 10^{4}$ & NM & 0.994 & 14.4 & & & 2.84 & (112) \\
\hline SL & 649 & $4 / 0$ & $0.05 \mu \mathrm{m} \mathrm{Al}{ }_{2}{ }_{3}$ & $1.1 \times 10^{4}$ & NM & 1.380 & 20.1 & & & 2.84 & (112) \\
\hline SL & 649 & $4 / 0$ & $0.05 \mu \mathrm{m} \mathrm{Al} \mathrm{O}_{2}^{2} \mathrm{O}_{3}^{3}$ & $1.1 \times 10^{4}$ & NM & 1.281 & 18.6 & & & 2.84 & (112) \\
\hline $\mathrm{DL}$ & 649 & $4 / 0$ & $0.05 \mu \mathrm{m} \mathrm{Al}{ }_{2}^{\circ}{ }_{3}^{\circ}$ & $8.07 \times 10^{6}$ & $6.03 \times 10^{7}$ & 0.507 & 7.4 & 0.134 & 1.928 & 2.84 & (112) \\
\hline SL & \multicolumn{2}{|c|}{ As received } & 600 -grit SiC & $6.76 \times 10^{2}$ & NM & 0.049 & 0.71 & & & 0.18 & $(7.2)$ \\
\hline SL & \multicolumn{2}{|c|}{ As received } & 600 -grit SiC & $8.18 \times 10^{2}$ & NM & 0.058 & 0.84 & & & 0.18 & (7.2) \\
\hline
\end{tabular}

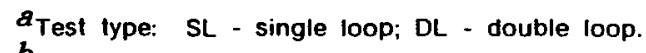

$b_{N M}$ - not measured. 
Table 3. Comparative EPR lest data for type 304L stainless steel plate; Work Request 7796 (grain size 6)

\begin{tabular}{|c|c|c|c|c|c|c|c|c|c|c|c|c|}
\hline \multirow[b]{2}{*}{$\begin{array}{l}\text { Test } \\
\text { type } 2\end{array}$} & \multicolumn{2}{|c|}{ Sensilization } & \multirow{2}{*}{$\begin{array}{l}\text { Specimen } \\
\text { surface } \\
\text { linish }\end{array}$} & \multicolumn{3}{|c|}{ Peak currents } & \multicolumn{2}{|c|}{$\begin{array}{c}\text { Reactivalion } \\
\text { integrated current }\end{array}$} & \multicolumn{2}{|c|}{ Current ratios } & \multicolumn{2}{|c|}{ Corrosion test data } \\
\hline & $\begin{array}{l}\text { Temperature } \\
\left({ }^{\circ} \mathrm{C}\right)\end{array}$ & $\begin{array}{l}\text { Time } \\
(\mathrm{h} / \mathrm{min})\end{array}$ & & $\ln _{(\mu A)}$ & & $\stackrel{I_{A}}{(\mu \mathrm{m})}$ & $\begin{array}{c}0 \\
\text { (C) }\end{array}$ & $\begin{array}{c}P_{A} \\
\left(\mathrm{C} / \mathrm{cm}^{2}\right)\end{array}$ & $\begin{array}{l}\text { As read } \\
I_{A} / I_{A}\end{array}$ & $\begin{array}{l}\text { Normalized } \\
I_{R} I_{A}\end{array}$ & $\begin{array}{r}\text { aver } \\
{[\mathrm{mm} / \text { year }}\end{array}$ & $\begin{array}{l}\text { rale } \\
\text { Is/year)] }\end{array}$ \\
\hline SL & 649 & $1 / 0$ & 600-grit sic & $1.494 \times$ & $\times 10^{2}$ & $\mathrm{NM}^{b}$ & 0.011 & 0.27 & & & 0.24 & (9.6) \\
\hline SL & 649 & $1 / 0$ & 600-grit SiC & $9.441 \times$ & $\times 10^{2}$ & NM & 0.117 & 2.86 & & & 0.24 & $(9.6)$ \\
\hline SL & 649 & $1 / 0$ & 600-grit SiC & $7.987 \times$ & $\times 10^{2}$ & NM & 0.054 & 1.32 & & & 0.24 & $(9.6)$ \\
\hline $\mathrm{SL}$ & 619 & $1 / 0$ & $0.05 \mu \mathrm{m} \mathrm{A1}{ }_{2}{ }_{3}$ & 2.7 & & NM & 0.000 & 0.00 & & & 0.24 & (9.6) \\
\hline SL & 649 & $1 / 0$ & $0.05 \mu \mathrm{m} \mathrm{A1}{ }_{2} O_{3}$ & 5.1 & & NM & 0.002 & 0.05 & & & 0.24 & $(9.6)$ \\
\hline SL & 649 & $1 / 0$ & $0.05 \mu \mathrm{m} \mathrm{A1}{ }_{2} O_{3}$ & 18.6 & & NM & 0.008 & 0.195 & & & 0.24 & $(9.6)$ \\
\hline $\mathrm{DL}$ & 649 & $1 / 0$ & $0.05 \mu \mathrm{m} \mathrm{A1} 1_{2}^{0}$ & 3.7 & $\times 10^{3}$ & $6.24 \times 10^{7}$ & 0.000 & 0.00 & $0.059 \times 10^{-3}$ & $1.5 \times 10^{-3}$ & 0.24 & (9.6) \\
\hline SL & 649 & $2 / 0$ & 600-grit Sic & 1.406 & $\times 10^{2}$ & NM & 0.11 & 0.27 & & & 0.24 & (9.6) \\
\hline SL & 649 & $2 / 0$ & 600.gril SiC & 9.393 & $\times 10^{2}$ & NM & 0.064 & 1.56 & & & 0.24 & $(9.6)$ \\
\hline SL & 649 & $2 / 0$ & 600-grit SiC & 5.126 & $\times 10^{2}$ & NM & 0.035 & 0.86 & & & 0.24 & $(9.6)$ \\
\hline SL & 649 & $2 / 0$ & $0.05 \mu \mathrm{m} \mathrm{Al}_{2} \mathrm{O}_{3}$ & 12.4 & & NM & 0.001 & 0.03 & & & 0.24 & $(9.6)$ \\
\hline SL & 649 & $2 / 0$ & $0.05 \mu \mathrm{m} \mathrm{A1}{ }_{2}^{2} 0_{3}^{3}$ & 29.5 & & NM & 0.003 & 0.07 & & & 0.24 & $(9.6)$ \\
\hline $\mathrm{DL}$ & 649 & $2 / 0$ & $0.05 \mu \mathrm{m} \mathrm{A1}{ }_{2}^{2} \mathrm{O}_{3}^{3}$ & 3.9 & $\times 10^{3}$ & $5.94 \times 10^{7}$ & 0.000 & 0.00 & $0.066 \times 10^{-3}$ & $1.6 \times 10^{-3}$ & 0.24 & $(9.6)$ \\
\hline SL & 649 & $3 / 0$ & 600-gril SiC & 1.171 & $\times 10^{2}$ & NM & 0.010 & 0.25 & & & 0.26 & $(10.2)$ \\
\hline SL & 649 & $3 / 0$ & 600-grit SiC & 6.327 & $\times 10^{3}$ & NM & 0.390 & 9.54 & & & 0.26 & $(10.2)$ \\
\hline SL & 649 & $3 / 0$ & 600 -grit SiC & 8.153 & $\times 10^{2}$ & NM & 0.055 & 1.34 & & & 0.26 & $(10.2)$ \\
\hline SL & 649 & $3 / 0$ & $0.05 \mu \mathrm{m} \mathrm{A1}{ }_{2}{ }_{3}$ & 12.4 & & NM & 0.001 & 0.024 & & & 0.26 & $(10.2)$ \\
\hline SL & 649 & $3 / 0$ & $0.05 \mu \mathrm{m} \mathrm{A} 1_{2}^{2} \mathrm{O}_{3}$ & 6.3 & & NM & 0.001 & 0.024 & & & 0.26 & $(10.2)$ \\
\hline $\mathrm{DL}$ & 649 & $3 / 0$ & $0.05 \mu \mathrm{m} \mathrm{A1}{ }_{2}^{2} 0_{3}^{3}$ & 3.8 & $\times 10^{3}$ & $6.30 \times 10^{7}$ & 0.001 & 0.024 & $0.060 \times 10^{-3}$ & $1.6 \times 10^{-3}$ & 0.26 & (10.2) \\
\hline
\end{tabular}

$a_{\text {Test lype: SL - single loop; DL - double loop. }}$

$b_{\mathrm{NM}}$ - not measured. 
Table 4. Comparative EPR test data for type 316 stainless steel plate; Work Request 7884 (grain size 3.5)

\begin{tabular}{|c|c|c|c|c|c|c|c|c|c|}
\hline \multirow{2}{*}{$\begin{array}{l}\text { Test } \\
\text { type }\end{array}$} & \multicolumn{2}{|c|}{ Sensitization } & \multirow{2}{*}{$\begin{array}{l}\text { Specimen } \\
\text { surface } \\
\text { finish }\end{array}$} & \multicolumn{2}{|c|}{ Peak currents } & \multicolumn{2}{|c|}{$\begin{array}{l}\text { Reactivation } \\
\text { integrated current }\end{array}$} & \multicolumn{2}{|c|}{$\begin{array}{c}\text { Corrosion test data } \\
\text { average rate }\end{array}$} \\
\hline & $\begin{array}{l}\text { Temperature } \\
\left({ }^{\circ} \mathrm{C}\right)\end{array}$ & $\begin{array}{l}\text { Time } \\
(\mathrm{h} / \mathrm{min})\end{array}$ & & $\begin{array}{c}I_{R} \\
(\mu A)\end{array}$ & $\begin{array}{c}\mathrm{I}_{A} \\
(\mu \mathrm{A})\end{array}$ & $\begin{array}{r}Q \\
(C)\end{array}$ & $\begin{array}{c}P_{A} \\
\left(C / \mathrm{cm}^{2}\right)\end{array}$ & {$[\mathrm{mm} / \mathrm{ye}$} & Is/year)] \\
\hline SL & \multirow{2}{*}{\multicolumn{2}{|c|}{$\begin{array}{l}\text { Solution annealed } \\
\text { Solution annealed }\end{array}$}} & $0.05 \mu \mathrm{A1}_{2} \mathrm{O}_{3}$ & 10. & NM ${ }^{b}$ & 0.001 & 0.06 & 0.18 & (7.2) \\
\hline SL & & & $0.05 \mu A 1_{2}^{0} 0_{3}$ & 14.7 & NM & 0.001 & 0.06 & 0.18 & (7.2) \\
\hline SL & 680 & $0 / 30$ & $0.05 \mu \mathrm{Al}_{2}{ }_{2}{ }_{3}$ & 46.3 & NM & 0.003 & 0.17 & & NM \\
\hline SL & 680 & $0 / 30$ & $0.05 \mu \mathrm{A1}_{2} \mathrm{O}_{3}$ & 51.8 & NM & 0.003 & 0.17 & & NM \\
\hline SL & 668 & $1 / 0$ & $0.05 \mu \mathrm{m} \mathrm{A1}{ }_{2}{ }_{3}$ & 68.2 & NM & 0.004 & 0.23 & 0.15 & $(6.0)$ \\
\hline SL & 668 & $1 / 0$ & $0.05 \mu \mathrm{m} \mathrm{A1}{ }_{2} \mathrm{O}_{3}$ & 56.2 & NM & 0.003 & 0.17 & 0.15 & $(6.0)$ \\
\hline SL & 659 & $2 / 0$ & $0.05 \mu \mathrm{m} \mathrm{A1}{ }_{2}{ }_{3}$ & 86.2 & NM & 0.005 & 0.29 & 0.15 & $(6.0)$ \\
\hline SL & 659 & $2 / 0$ & $0.05 \mu \mathrm{m} \mathrm{A1}{ }_{2}^{2} 0_{3}^{3}$ & 84.7 & NM & 0.005 & 0.29 & 0.15 & $(6.0)$ \\
\hline SL & 675 & $3 / 0$ & $0.05 \mu \mathrm{m} \mathrm{A1}{ }_{2}{ }_{3}$ & 675.6 & NM & 0.036 & 2.10 & 0.15 & $(6.0)$ \\
\hline SL & 675 & $3 / 0$ & $0.05 \mu \mathrm{m} \mathrm{A1}{ }_{2}{ }_{3}$ & 842.6 & NM & 0.045 & 2.62 & 0.15 & $(6.0)$ \\
\hline
\end{tabular}

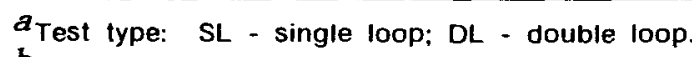

$b_{\mathrm{NM}}$ - not measured. 
Table 5. Comparative EPR test data for type 304L stainless steel plate; Work Request 7698 (grain size 3)

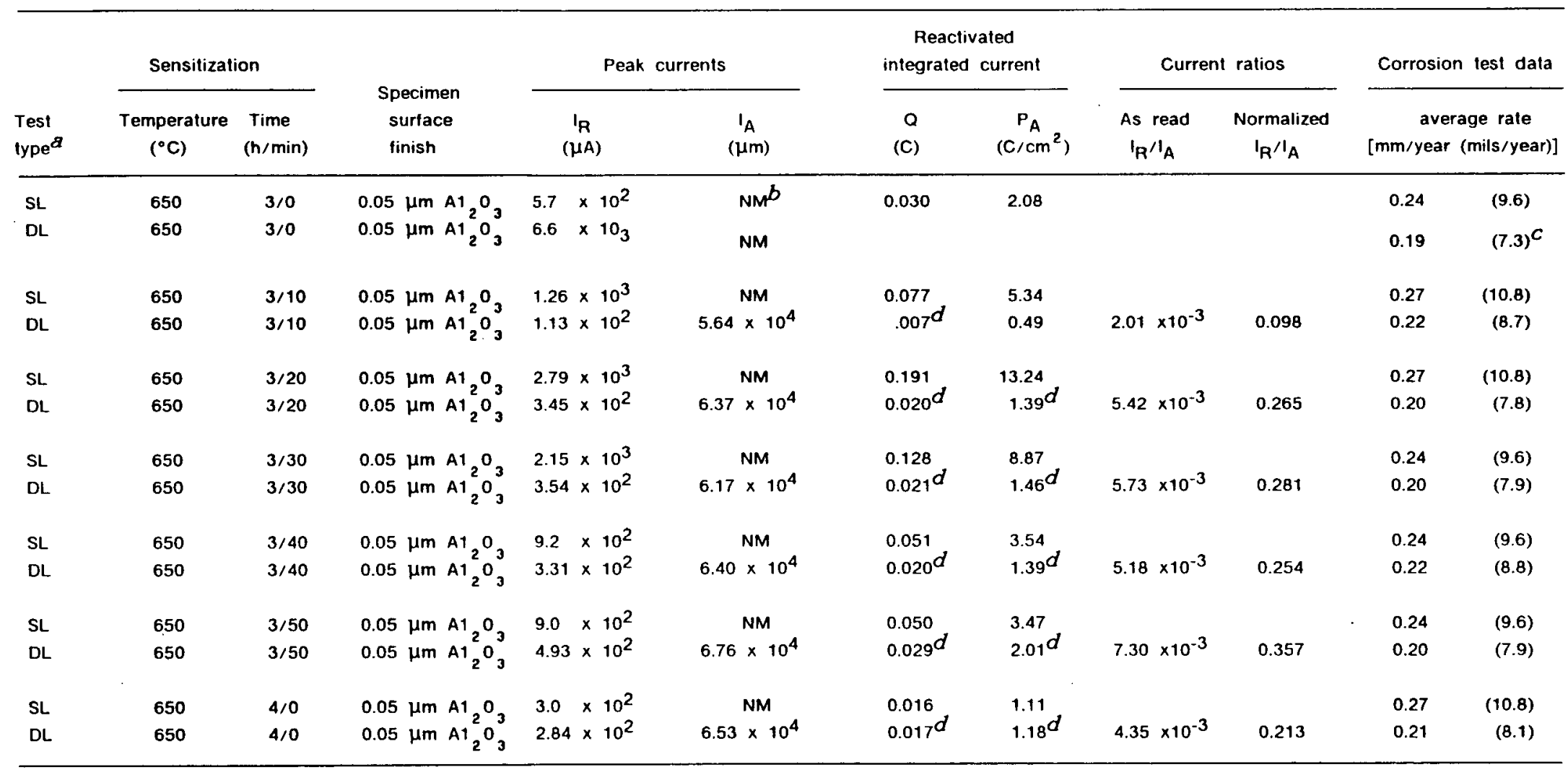

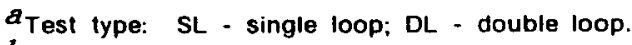

$b_{\mathrm{NM}}$ - not measured.

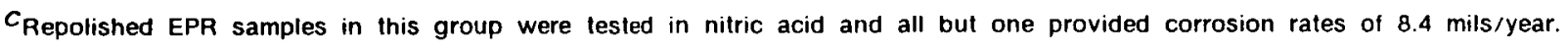

The 3-h sample was only 7.2 mils/year.

$d_{\text {SL }}$ type data derived trom reactivation loop of double-loop test. 


\section{DISCUSSION OF FINDINGS}

The screening nature of the experimental tests discussed here precludes any detailed evaluation of the EPR procedures because they involve a range of heat-treatment times, a variability in the starting stock compositions, and undefined presensitization histories. However, the data do permit a qualitative assessment of the potential application of the EPR type of testing as a replacement for the nitric acid testing.

An examination of the nitric acid corrosion rate data given in Tables 2 through 5 clearly shows that in these limited experiments, intermediate levels of sensitization were not achieved. Our data seem to indicate that there is an incubation period for the sensitization of type $304 \mathrm{~L}$ stainless steel at $650^{\circ} \mathrm{C}$. This observation is similar to that of the data presented by Loria, ${ }^{10}$ where there was an abrupt change in the sensitization of his AOD heat in continuous cooling sensitization tests. This result may be associated with the nucleation of chromium carbide precipitates that, once formed, grow rapidly. This hypothesis is supported by a comparison of the data in Tables 2 and 4 . The compositions of the two steels suggest that they were from the same plate and stock. However, the large grain size of the material tests reported in Table 4 indicates high-temperature solution anneal before sensitization, which could have dissolved any intergranular carbide that might have been present in the material tested and reported in Table 2. This condition would increase the nucleation incubation period for the large grain material and account for the differences in sensitization after $4 \mathrm{~h}$ at $650^{\circ} \mathrm{C}$. This result is in agreement with the studies of continuous cooling sensitization reports by Solomon 11,19,20 and others. Such studies have shown that susceptibility to sensitization is significantly reduced by starting at higher temperatures $\left(>1000^{\circ} \mathrm{C}\right)$. Sensitization occurs at faster cooling rates if the peak temperature before cooling is in the 800 to $900^{\circ} \mathrm{C}$ range. Although these observations do not assist in the definition of an alternative test, they do emphasize the need to qualify all materials to be used in nitric acid service.

Although these tests clearly indicate that the current EPR procedures are not suitable substitutes for the nitric acid testing, they do suggest that this test or a modified version of it might be developed to supplant the qualitative ASTM Practice A oxalic acid etch test with a quantitative test suitable for accepting, but not rejecting, type $304 \mathrm{~L}$ material. Because the overall corrosion resistance of the material and not just the extent of intergranular sensitization is of importance here, the data should be examined in terms of those parameters available from the EPR type of test that offer the most promise of providing an appropriate quantitative figure of merit. With this in mind, the data for the highly polished samples only from Tables 2, 3, 5, and 6 were recompiled, and the various parameter data as a function of the nitric acid corrosion rates were plotted. 
Before a discussion of the plots, the parameters will be examined. The currently proposed EPR procedures use $P_{a}$ or $I_{R} / I_{A}$, respectively, as a figure of merit for the single- and double-loop tests. $\mathrm{P}_{\mathrm{a}}$ is derived from $Q$, the integrated reactivation scan current flow from the entire sample surface, by assuming that all of this current flows through the grain boundary sensitized area. This assumption must be verified by posttest examination of the test surface because significant pitting or end-grain attack negates its utility. The $P_{a}$ value is highly dependent on the peak reactivation current $\left(I_{R}\right)$ and also on the accurate determination of the grain size and the assumption defining grain boundary width. For very low degrees of grain boundary sensitization, the literature indicates a good correlation with stress-corrosion cracking in oxygenated water. The double-loop procedure uses the ratios between the peak $I_{R}$ and the peak current flowing during the anodic scan $\left(I_{A}\right)$. The rationale for this correlation assumes that the variable overall corrosion resistance, because of compositional differences and pitting end-grain attack, will affect both the $I_{R}$ and $I_{A}$ equally; thus, the ratio should be restricted to defining the susceptibility of a sample to intergranular sensitization. When the $I_{R}$ values are normalized to the GBA, the literature data for this ratio show an excellent correlation with $P_{A}$ values. The ratios also correlate with the intergranular sensitization evaluation tests in ASTM A-262 that are insensitive to pitting or to end-grain attack.

Because interest here is in the overall corrosion resistance, the raw data derived from our EPR tests without normalization to GBAs (for all values except $P_{a}$ quoted in Table 6) have been used. Note that the exposed surface area in all of our screening tests is limited to $1 \mathrm{~cm}^{2}$ by the holder. Therefore, the current values read by the instruments in amperes reported for $I_{R}$ and $I_{A}$ in the table are equivalent to amperes per square centimeter, and the $Q$ values are equivalent to coulombs per square centimeter. Therefore, direct comparisons of the test data are legitimate.

The IA values are not plotted as a function of corrosion rates because there is no known correlation of such data. This peak current flow occurs in the anodic scan when the applied voltage reaches the primary passivation potential. The current peaks at this potential provide only a qualitative evaluation of the ease of passivation.

The variation in current during reactivation of a passivated sample is plotted against the nitric acid corrosion rate in Fig. 4 . This current $\left(I_{R}\right)$ derived from single-loop EPR tests has been used instead of $\mathrm{P}_{a}$ by some investigators as a measure of sensitization. ${ }^{16}$ Here, double-loop procedure values have been plotted together with single-loop procedure values. Although there are probably some surface morphology differences associated with the mode of reaching the passivation potential, the time at potentials above $200 \mathrm{mV}$ is the same for both procedures. However, in this small data group, the relative values of $I_{R}$ from the two procedures do not correlate well, ranging from essentially identical values differing by three orders of magnitude. Despite this range of values, the data do indicate a separation of the high corrosion rate sample currents from those of the low corrosion rate sample. 
Table 6. Selected data ${ }^{a}$ from Tables 2,3 , and 5

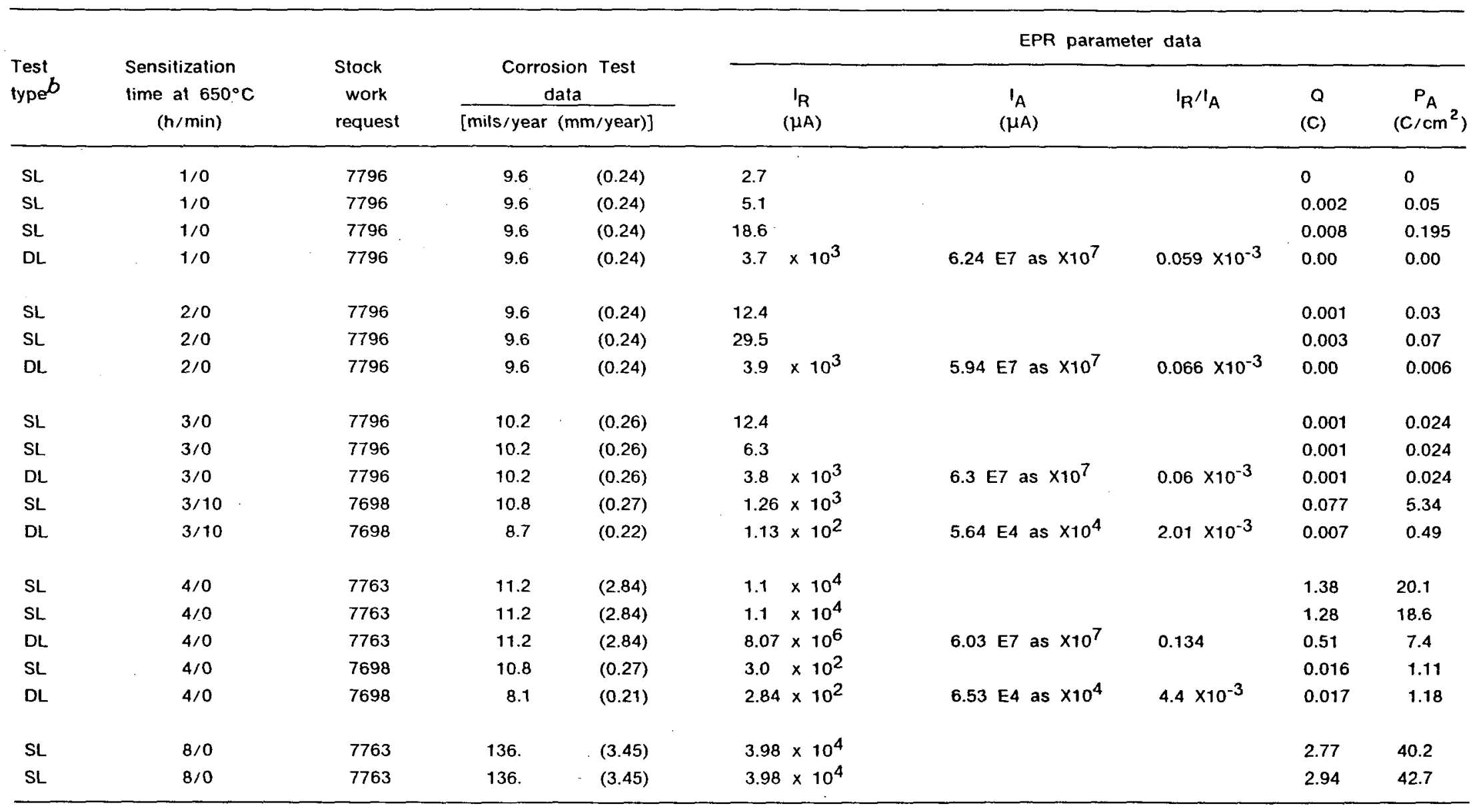

$a_{\text {Only those data from test in which the EPR specimen finish was } 0.5 \mu \mathrm{m} \mathrm{Al}} \mathrm{O}_{3}$.

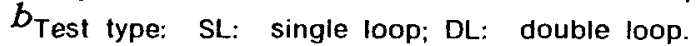


ORNL-DWG 86C-3987 ETD

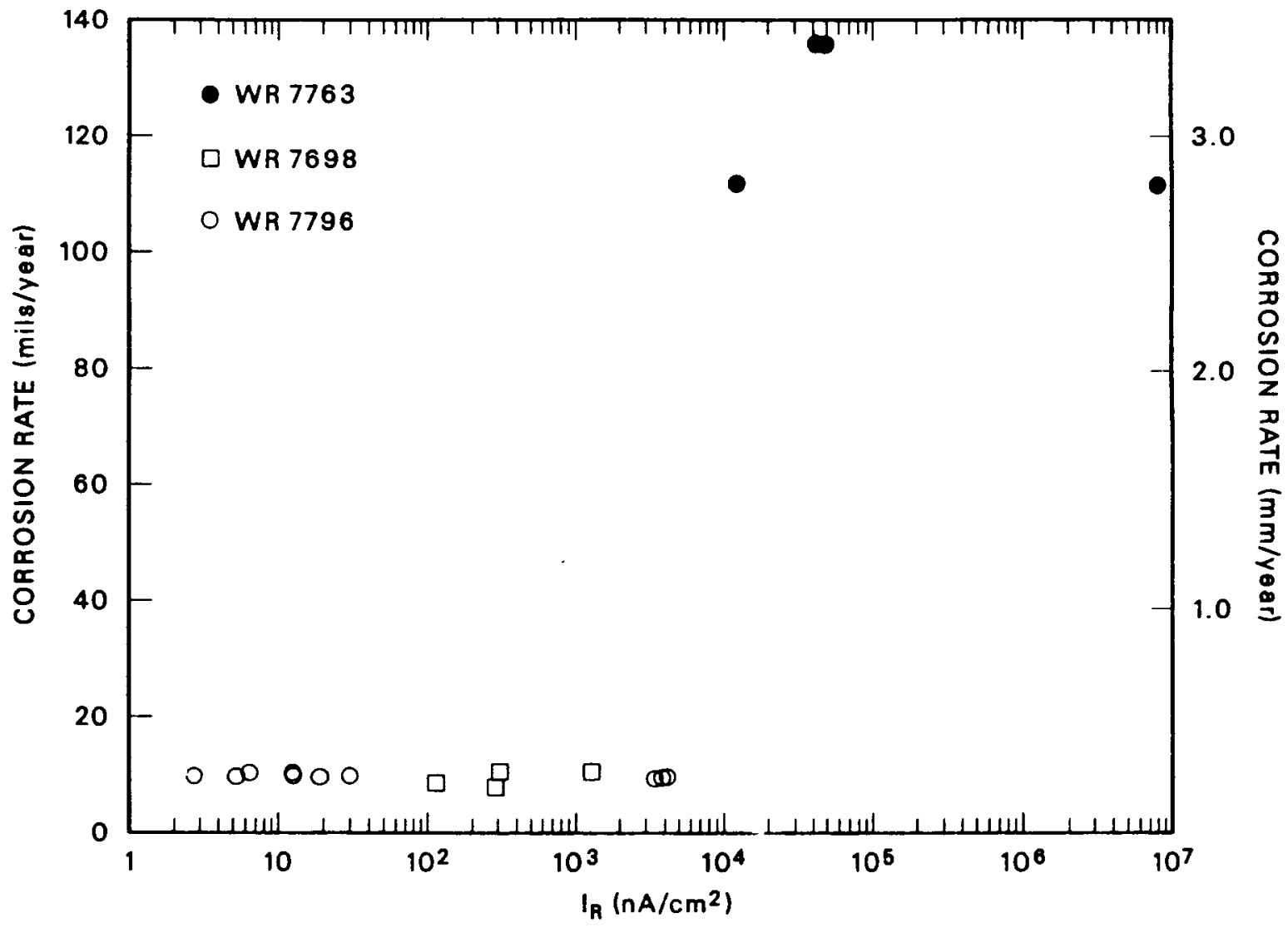

Fig. 4. Average nitric acid test corrosion rates as a function of peak anodic current during an EPR potentiokenetic reactivation scan.

As seen in Fig. 5, the very limited amount of data comparing the $I_{R} / I_{A}$ ratio from the double-loop procedure with corrosion rates appears to show a more distinct separation between high and low corrosion rate samples. Unfortunately, sufficient data are not available to verify this.

Figure 6 is a plot of the reactivation loop coulombs (Q) as a function of the total area of the sample $\left(1 \mathrm{~cm}^{2}\right)$. Again, data from both single- and double-loop procedures are included. As seen in Table 5, the comparative values for similar samples are not as dissimilar as the $I_{R}$ values and do indicate a distinct separation between high and low corrosion rate samples.

The distinction between high and low corrosion rate samples as a function of integrated currents (Q) during reactivation is far less obvious when this value is assigned to GBAs only $\left(P_{a}\right)$ (Fig. 7). The lack of distinction appears to be associated with the significant differences in grain sizes of the samples and their different normalization factors. Table 7 tabulates GBA and normalization factors for ASTM grain sizes 1 through 10 . The need for accuracy in determining the grain size is apparent for precise definitions, but even a change of two sizes only involves a factor of two changes in the $P_{a}$ value. Thus, grain size would 
ORNL-DWG $86 C-3988$ ETD

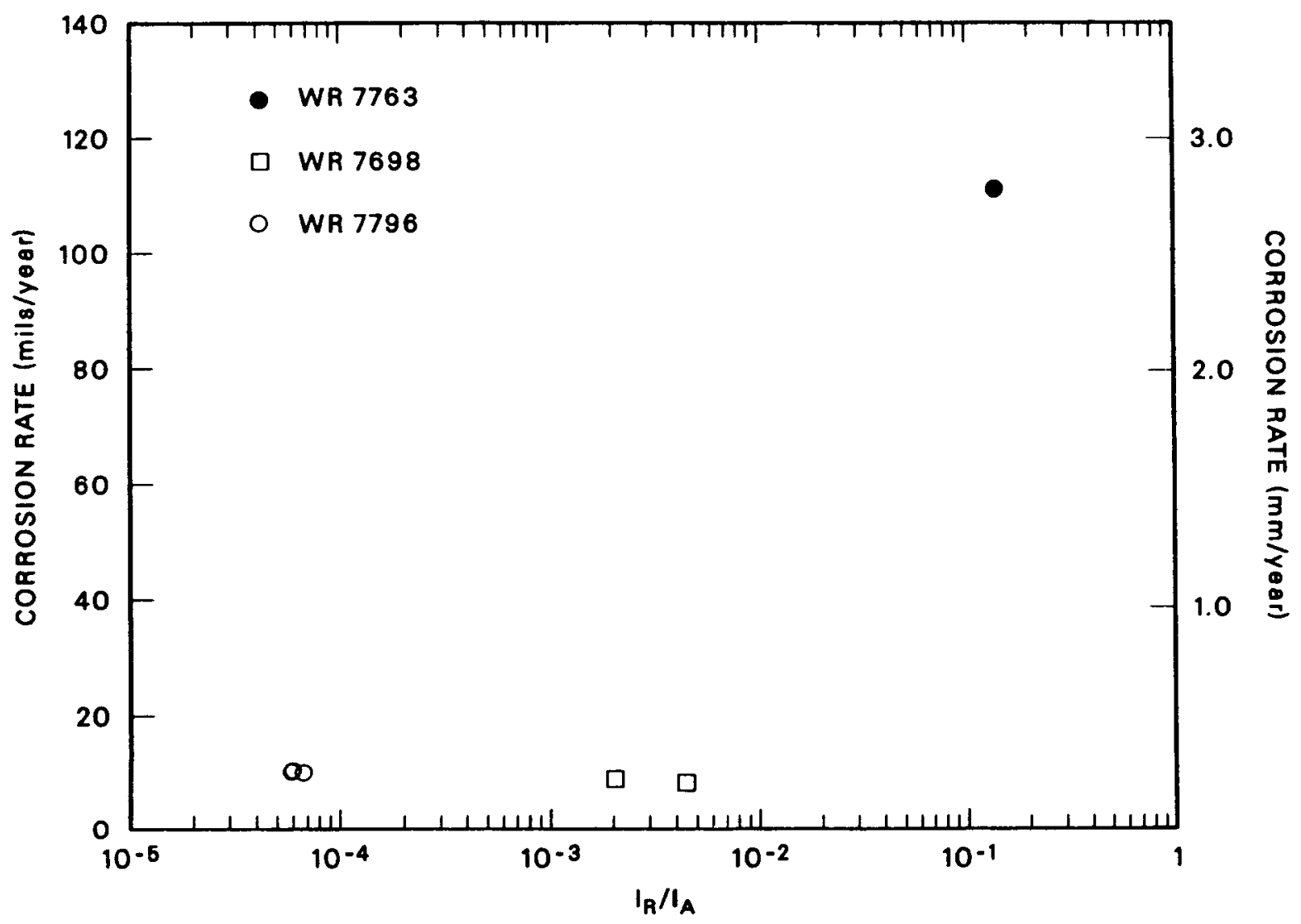

Fig. 5. Average nitric acid corrosion rates as a function of the ratios of peak anodic currents measured during EPR potentiokinetic passivation $\left(I_{A}\right)$ and reactivation $\left(I_{A}\right)$ scans.

not account for the differences between Figs. 3 and 4 . The unnormalized values may offer an improved distinction where all forms of corrosion, not just grain boundary attack, are of interest.

Both the current ratio and the integrated current during reactivation-described in terms of sample area, not GBA-may offer figures of merit suitable for accepting type $304 \mathrm{~L}$ material without submitting it to the nitric acid test. However, a significant amount of testing will be required to define an appropriate figure of merit that would be reliable and still significantly reduce the amount of nitric acid testing. Clarke ${ }^{5}$ has proposed a conservative $P_{a}$ value of $2 \mathrm{C} / \mathrm{cm}^{2}$ for the single-loop test acceptance of type 304 stainless steel to be welded and used in the nuclear industry. Such a limit would be approximately equal to an $I_{R} / I_{A}$ ratio of 0.001 for the double-loop test procedure, as shown by Majidi and Streicher. ${ }^{\text {: }}$ Such a limit would apparently ensure the oxalic acid etch test (ASTM A-262, Practice A) step-structure observation. Application of these limitations on EPR test data to future screening experiments appears to be appropriate because the test would accept most of the sensitized type 304L that passed the nitric acid tests. Only the tests reported in Table 5 would fail both types of EPR 
ORNL-DWG 86C-3989 ETD

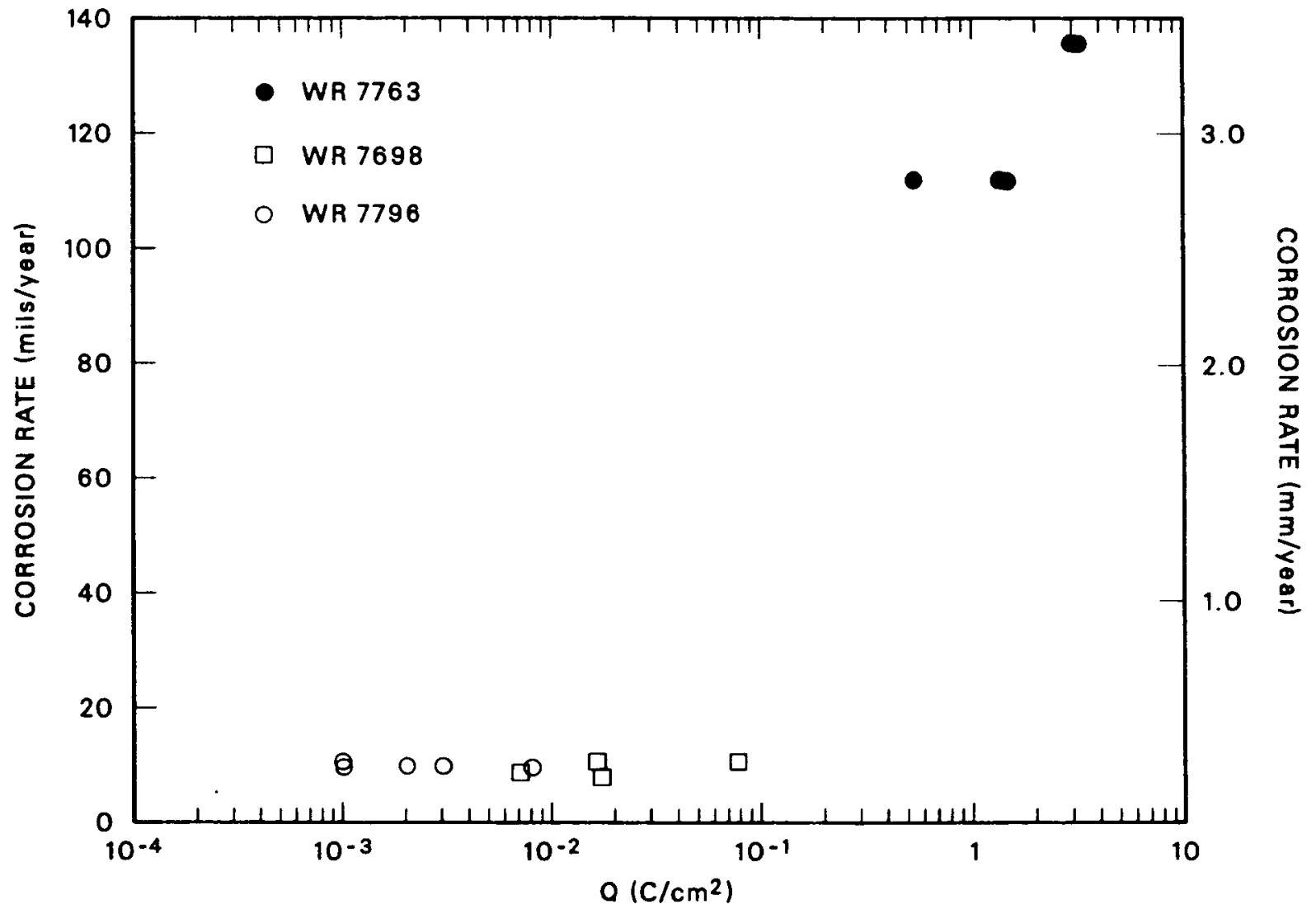

Fig. 6. Average nitric acid test corrosion rates as a function of integrated current flow through the specimen surface during a potentiokinetic reactivation scan.

tests and not the nitric acid test. Thus, both the information derived from the literature search and the limited experimental programs described here strongly indicate that the EPR tests can be used as a quantitative substitute for the qualitative oxalic acid test currently used by industry to accept, but not reject, austenitic stainless steels intended for use in a nitric acid medium. 
ORNL-DWG 86C-3990 ETD

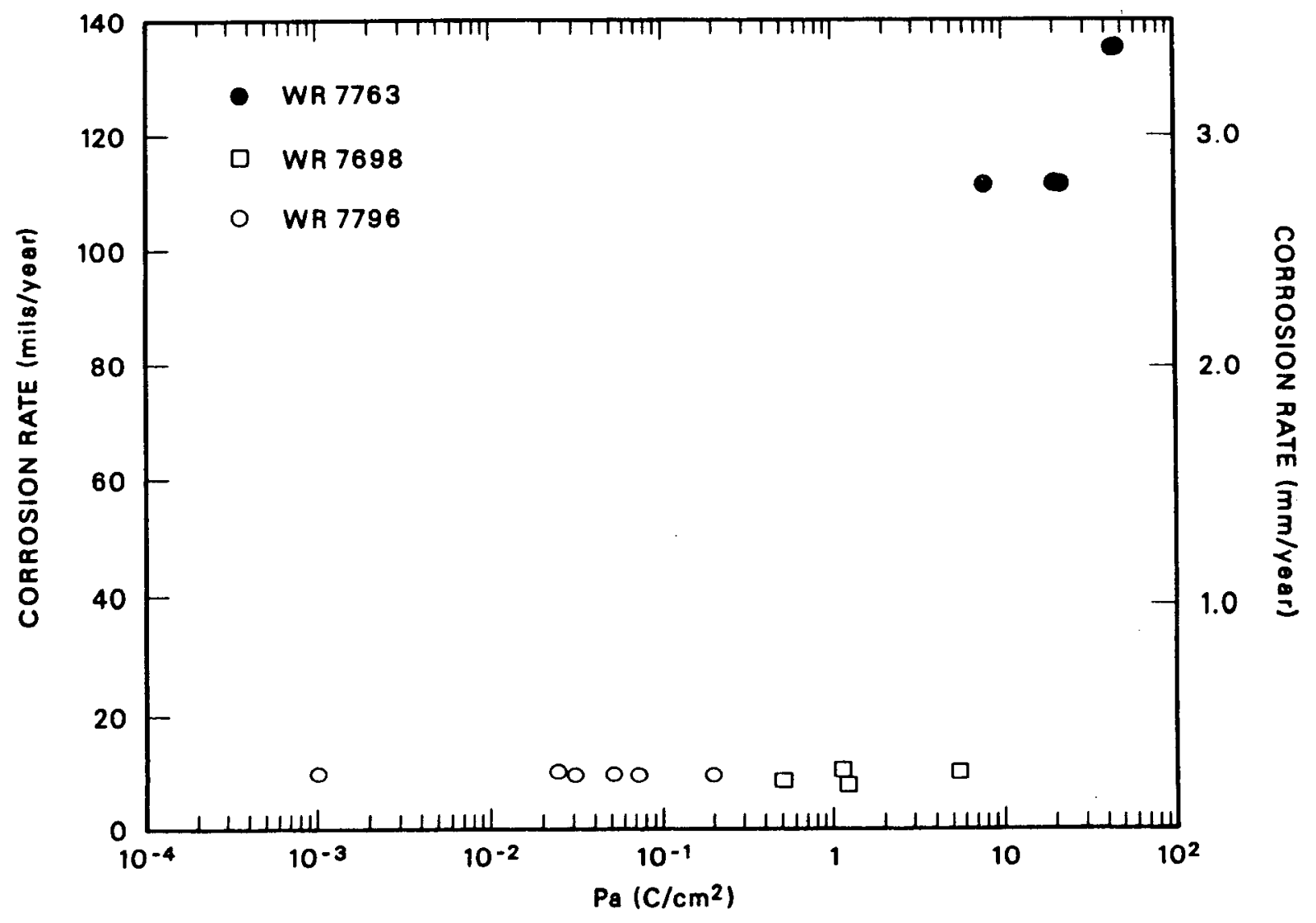

Fig. 7. Average nitric acid test corrosion rates as a function of integrated current flow during an EPR reactivation scan assumed to flow through the grain boundary area only.

Table 7. Effects of grain size on GBAs and normalization of EPR integrated current to the grain boundaries ${ }^{a}$

\begin{tabular}{rccc}
\hline $\begin{array}{l}\text { Grain } \\
\text { size }\end{array}$ & $\begin{array}{c}\text { Quantity } \\
\text { (grains/in. }^{2} \text { ) }\end{array}$ & GBA & $\begin{array}{c}\text { Q normalization } b \\
(1 / G B A)\end{array}$ \\
\hline 1 & $<1.5$ & 0.0072 & 138.72 \\
2 & $1.5-3.0$ & 0.0102 & 98.05 \\
3 & $3-6$ & 0.0144 & 69.31 \\
4 & $6-12$ & 0.0204 & 48.99 \\
5 & $12-24$ & 0.0289 & 34.63 \\
6 & $24-48$ & 0.0409 & 24.47 \\
7 & $48-96$ & 0.0578 & 17.30 \\
8 & $96-102$ & 0.0818 & 12.23 \\
9 & $192-384$ & 0.1157 & 8.64 \\
10 & $384-768$ & 0.1637 & 6.109 \\
\hline
\end{tabular}

$a_{\text {Where GBA }}=$ As $\left[5.09544 \times 10^{-3} \exp (0.3469 G s)\right]$, assume $A_{S}=1 \mathrm{~cm}^{2}$ (exposed sample suriace).

$b_{P_{\mathbf{a}}}=Q / G B A$ in EPR single loop test, or $P_{a}=\frac{I_{R}}{}$

in EPR double-loop lests. $\mathrm{I}_{A}(\mathrm{GBA})$ 


\section{CONCLUSIONS}

Based on the literature survey and the screening tests described here, the use of the currently proposed EPR procedures as a substitute for the established nitric acid corrosion test would be inappropriate at this time. This conclusion is particularly true for materials being purchased for the EURI program, where materials compatibility qualification testing should be based on established experience.

The above conclusion does not mean that the findings were negative. In fact, all available data indicate that some modification of the EPR test will be very useful in screening materials for nitric acid service. Although such tests may not be used to reject lots, they will be useful in providing a quantitative means of identifying materials that can be accepted without being subjected to the nitric acid test. To achieve this status, two areas must be developed:

1. The current EPR procedures must evolve into a standard practice procedure acceptable to industry. Basically, this means the evolu. tion of an ASTM Standard Practice, which would ensure the availability of such tests from the materials suppliers and improved reliability in the reproducibility of the data. This area of development appears very likely because of the emphasis being derived from the nuclear power industry.

2. The second area is more provincial in character. As stated in the the Introduction, the nitric acid test does not provide reliable corrosion data for the wide variety of nitric acid media encountered at the Y-12 Plant. However, material passing this test has generally given good service. A similar experience data base should be developed for materials passing established EPR test criteria. Evolution for this criteria will probably be based on the experience, as was the $0.945-\mathrm{mm} /$ year (24-mils/year) limit for the nitric acid test. Development of this data base could also serve alternate purposes. In-house EPR testing of stock purchased with nitric acid testing certification could provide an alternative independent check. Assuming that the resulting values of $\mathrm{P}_{\mathrm{a}}$ are $<2 \mathrm{C} / \mathrm{cm}^{2}$ or $\mathrm{I}_{\mathrm{R}} / \mathrm{I}_{\mathrm{A}}$ values are $<0.001$, no in-house confirmatory nitric acid test would be required. These data, together with selective in-plant component monitoring, would provide the needed data base for permitting EPR testing when an ASTM standard practice is defined. With the significant modifications involved in the EURI program, there is a real opportunity to develop this data base. 


\section{REFERENCES}

1. M. A. Streicher, "Theory and Application of Evaluation Tests for Detecting Susceptibility to Intergranular Attack in Stainless Steels and Related Alloys - Problems and Opportunities," pp. 3-84 in Intergranular Corrosion of Stainless Alloys, ASTM STP 656, R. F. Steigerwald, ed., American Society for Testing and Materials, 1978.

2. A. Toboada and L. Frank, "Intergranular Corrosion in Nuclear Systems," p. 85-98 Intergranular Corrosion of Stainless Alloys, ASTM STP 656, R. F. Steigerwald, ed., American Society for Testing and Materials, 1978.

3. W. L. Clarke, R. L. Cowan, and W. L. Walker, "Comparative Methods for Measuring Degree of Sensitization in Stainless Steel," pp. 99-132 in Intergranular Corrosion of Stainless Alloys, ASTM STP 656, R. F. Steigerwald, ed., American Society for Testing and Materials, 1978.

4. W. L. Clarke and D. C. Carlson, "Nondestructive Measurement of Sensitization of Stainless Steel: Relation to High Temperature Stress Corrosion Behavior," Mater Perform, 16-23 (March 1980).

5. W. L. Clarke, The EPR Method for the Detection of Sensitization in Stainless Steels, NURGEG/CR-1095 (GEAP-2488) April 1981.

6. M. Akashi et al., "Evaluation of IGSCC Susceptibility of Austenitic Stainless Steels Using Electrochemical Methods," trans. BTSITS from Boshoku Gijutsu (Corrosion Engr), 29, p. 163.

7. A. P. Majidi and M. A. Streicher, "The Double Loop Reactivation Method for Detecting Sensitization in Type 304 Stainless Steel," Paper No. 261, Corrosion/84, April 2-6, 1984, New Orleans, Louisiana (available from NACE).

8. E. A. Loria, "Evaluating Tendency for Sensitization in Type 304 Stainless Steel via Jominy Bar Testing," J. Met., 31, 137-46 (June 1979).

9. E. A. Loria, "Studies of Fabrication - Related Sensitization in Type 304 Stainless Steel," J. Met., 31, 163-69 (December 1979).

10. E. A. Loria, "Intergranular Corrosion and End-Grain Pitting in Type 304 Stainless Steel by Various Methods," Corrosion 37 (8) 481-85 (1981).

11. H. D. Solomon, "Continuous Cooling Sensitization of Type 304 Stainless Steel," Corrosion 34 (6), 183-93 (June 1978). 
12. J. J. Echenrod and C. W. Kovach, "Effect of Nitrogen on the Sensitization, Corrosion, and Mechanical Properties of $18 \mathrm{Cr}-8 \mathrm{Ni}$ Stainless Steels," pp. $17-41$ in Properties of Austenitic Stainless Steels and Their Metals (Influence of light Chemistry Variations), ASTM STP 679, C. R. Brinkman and H. W. Garvin, eds., American Society for Testing and Materials, 1979.

13. E. A. Loria, "Perspective on Intergranular Corrosion of Type 304 Stainless Steel," J. Met., 35, 16-22 (October 1982).

14. S. J. Pawel and E. E. Stansbury, "Sensitization Behavior of Cast Stainless Steels Subjected to Weld Repair," Masters thesis, University of Tennessee, Knoxville, June 1983.

15. E. E. Stansbury, C. D. Lundin, and S. J. Pawel, Exemption of CF3M From Post Weld Repair Solution Treatment in ASTM A-744 - SFSA Project A-82/85 Progress Report, August 1984, The University of Tennessee, Knoxville, 1984.

16. C. D. Lundin, E. E. Stansbury, and C. H. Lee, The Effect of Welding Variables on Corrosion Behavior of Austenitic Stainless Steel, Progress Report, May 1984, The University of Tennessee, Knoxville, 1984.

17. C. D. Lundin, E. E. Stansbury, and C. H. Lee, The Effect of Welding Variables on Corrosion Behavior of Austenitic Stainless Steel, Progress Report, May 1984, The University of Tennessee, Knoxville, 1984.

18. A. P. Majidi and M. A. Streicher, "Potentiodynamic Reactivation Method for Detecting Sensitization in AISI 304 and 304L Stainless Steels," Corrosion 40 (8), 393-408 (August 1984).

19. H. D. Solomon, "The Influence of Prior Deformation on Continuous Cooling Sensitization of Type 304 Stainless Steel," Corrosion 36 (7), 356-61 (July 1980).

20. H. D. Solomon, "The Influence of Composition on Continuous Cooling Sensitization of Type 304 Stainless Steel," Corrosion 40 (2), 51-60 (February 1984). 


\section{DISTRIBUTION}

\section{Department of Energy - Oak Ridge}

Foutch, J. L.

Poteat, R. M.

\section{Lawrence Livermore National Laboratory}

Clough, R. E./Galles, H. L.

Miller, G. H.

Ragaini, R. C.

Robbins, J. L.

Sanford, C. B.

Shuler, W. B./Wraith, C. L.

Technical Information Division

Werne, R. W./Grissom, M. L.

\section{Los Alamos National Laboratory}

Hoyt, H. C.

\section{Oak Ridge National Laboratory}

Devan, J. H.

Slaughter, G. M.

Thornton, P. T.

\section{Oak Ridge Y-12 Plant}

Bullock, J. S., IV

Burditt, R. B.

Clift, T. L.

Deroos, L. F.

Dillon, J. J.

Dodson, W. H./Googin, J. M.

Evans, P. A.

Fourman, J. F. Keith, A.

Kite, H. T.

Koger, J. W.

Kollie, T. G.

Mills, J. M., Jr.

Mustaleski, T. M., Jr.

Newman, T. D.

O'Hara, M. J.

Olsen, A. R.

In addition, this report is distributed in accordance with the Category UC-25, Materials as given in the Standard Distribution for Unclassified Scientific and Technical Reports, DOE/TIC-4500. 
Peters, A. H.

Renfro, G. W.

Riikola, A. J.

Smith, R. P.

Thompson, J. E.

Thrasher, T. H.

Walton, Y. W.

Weathersby, W. E.

Y-12 Central Files (master copy)

Y-12 Central Files (route copy)

Y-12 Central Files ( $Y-12$ RC)

$Y-12$ Central Files (5)

Paducah Gaseous Diffusion Plant

Walter, C. W.

Sandia National Laboratories - Livermore

Olson, D. M.

The University of Tennessee

Lundin, C. D.

Pawel, S. J. 